\title{
O Papel das Infraestruturas Ferroviárias nas Mudanças de Uso e Cobertura do Solo no MATOPIBA
}

\section{The Role of Railway Infrastructures in Land Use and Cover Change in MATOPIBA, Brazil}

\author{
Ícaro Neri Pereira de Souza ${ }^{1 *} \bowtie$ (D), Rodrigo Affonso de Albuquerque Nóbrega² $₫$ (D), Sónia \\ Maria Carvalho Ribeiro $₫$ (iD \\ 1Departamento de Geografia, Instituto de Geociências, Universidade Federal de Minas Gerais - \\ Belo Horizonte, Minas Gerais, Brasil \\ 2 Departamento de Cartografia, Instituto de Geociências, Universidade Federal de Minas Gerais - \\ Belo Horizonte, Minas Gerais, Brasil \\ E-mails: raanobrega@ufmg.br (RAAN); sonia.carvalhoribeiro@gmail.com (SMCR). \\ *E-mail para correspondência: icaro.neri@hotmail.com (INPS)
}

Recebido (Received): 29/08/2018

\begin{abstract}
Resumo: As mudanças do uso e cobertura do solo afetam e são resultantes de complexos processos naturais e socioeconômicos. A infraestrutura rodoviária exerce grande influência nessa dinâmica, contudo o papel das ferrovias nesse processo tem sido pouco debatido. No Brasil, a expansão da agropecuária nas últimas décadas tem demandado investimentos em transporte. Isso inclui o planejamento e construção de ferrovias na região formada pelos estados do Maranhão, Tocantins, Piauí e Bahia (MATOPIBA), uma das áreas com maior crescimento e expansão da produção agropecuária. Considerando este contexto, este trabalho tem como objetivo desenvolver uma modelagem espacialmente explícita explorando as associações entre a infraestrutura ferroviária (trilhos, pátios ferroviários e terminais intermodais) e a dinâmica de uso e cobertura do solo em uma área de $650.682 \mathrm{~km}^{2}$ no MATOPIBA. O modelo espacialmente explícito desenvolvido para o período 2000-2012 utilizou o método bayesiano dos pesos de evidência para explorar quais os determinantes espaciais das transições entre classes de cobertura do solo e o papel das infraestruturas ferroviárias de transporte nessas mudanças. Os resultados da modelagem forneceram subsídios para conhecer as variáveis e explicar as transições de uso e cobertura do solo no período investigado, também como compilar cenários preditivos do uso e cobertura do solo para as próximas décadas. A modelagem mostrou uma tendência no aumento das áreas destinadas para a produção agropecuária em detrimento das áreas com vegetação nativa . Os resultados também mostraram que as infraestruturas ferroviárias poderão alterar a configuração espacial na região, atraindo a produção agropecuária para os pontos nodais das novas infraestruturas.
\end{abstract}

Palavras-chave: Modelagem; LUCC; Soja; Ferrovia; SIG; Geoprocessamento.

\begin{abstract}
Land use/cover change (LUCC) can both affect and result of complex natural and socio-economic processes. The highway system is a key component for LUCC, however the role of railway infrastructure as a driver of the changes has been hardly ever in debate. In Brazil the steadily rise on large scale agro husbandry production has been demanding for railway infrastructure in states such as Maranhão, Tocantins, Piaui and Bahia (MATOPIBA), where agro husbandry production is steadily rising. In this context, the objective of this work is to develop a spatially explicit model to explore the associations between railway infrastructure (tracks, rail yards e intermodal facilities) and LUCC in an area of $650.682 \mathrm{~km}^{2} \mathrm{in}$ MATOPIBA. The model used the Baysian method of Weights of Evidence to explore the spatial determinants of land use transitions and their spatial determinants as well its associations to railway infrastructure. The model was calibrated with 2000-2012 data. This modelling approach was able to identify which variables and its ranges that can be associated to LUCC in MATOPIBA and this model was further used to simulate future scenarios of land use change in the coming decades. Our results clearly show a clear trend of increasing agro husbandry production and a trend of decreasing in native vegetation. Our results also
\end{abstract}


highlight that railway infrastructure can indeed be associated changes into spatial configuration of landscape mainly by attracting LUCC in the nodes of new railway infrastructures.

Keywords: Modelling; LUCC, Soy; Railway; GIS; Geoprocessing.

\section{Introdução}

A mudança do uso e cobertura é um fenômeno que ocorre naturalmente. A sua influência na perda de biodiversidade tem causas na indução antrópica e predatória dos recursos. Segundo Lapola et al (2014), as mudanças de uso e cobertura do solo são também conhecidas por afetar a provisão de serviços ecossistêmicos alterando as funções biológicas da paisagem, os modos de vida e desenvolvimento socioeconômico das populações. Nas últimas décadas, os estudos sobre as mudanças do uso e cobertura do solo, como Ibischet al. (2016) e Theobald (2010), mostram crescente complexidade abrangendo várias áreas do saber e procuram compreender questões extremamente intricadas em fenômenos que envolvem atores e variáveis do meio físico, ambientais, sociais e econômicos. Um crescente número de estudos tem explorado variáveis explicativas para as taxas de conversão do uso do solo com o objetivo de quantificar e predizer os padrões futuros de uso e cobertura do solo. Neste contexto, a influência das infraestruturas de transporte na dinâmica das mudanças da paisagem tem sido amplamente investigada quanto ao modal rodoviário, como, por exemplo, os trabalhos de Lima et al. (2013), Nobrega et al. (2012), Spellerberg (1998) e Trombulak e Frissell (2001).

Contudo, o papel das ferrovias na composição da cobertura e uso do solo tem sido pouco debatido. Uma consulta recente aos portais Science Direct e Google Scholar, realizada durante a concepção do presente estudo, revelou a existência de uma lacuna em relação trabalhos científicos destinados a investigar a influência de infraestruturas ferroviárias de transporte de carga nas mudanças de uso e cobertura do solo em escala regional. Embora indiretamente relacionados ao uso do solo, a literatura revela trabalhos que reportam a influência das ferrovias voltadas ao transporte de carga na economia regional (NOBREGA e STICH, 2012; KEELING, 2007; VENCOVSKY, 2006), bem como estudos relacionados ao impacto das infraestruturas ferroviárias nos ecossistemas, biomas, animais e/ou vegetais (KARLSON et al., 2016; HAN et al., 2014, FORMAN et al., 2003), e nas cidades (OLIVEIRA et al., 2018; MAES e VANELSLANDER, 2010). No entanto, a investigação quantitativa desses efeitos em escala macro regional é ainda uma lacuna.

Trabalhos como Vieira (2015) e Silveira (2003) abordam as características macro logísticas da produção agrícola e industrial brasileira e enfatizam a necessidade da construção e operacionalização de novas ferrovias para suprir, de forma sustentável, o déficit logístico brasileiro. Embora com volumes ainda baixos, a utilização de ferramentas e análises geoespaciais são gradativamente empregadas em estudos de planejamento de transportes (NOBREGA et al., 2016 ; ARAÚJO et al, 2015, SOUZA et al., 2014), mais especificamente utilizando análises multicritério ou de outras técnicas em ambiente SIG para quantificar indicadores de viabilidade para a identificação de corredores ferroviários e a localização ótima de áreas de armazenagem e transbordo de cargas. Contudo, a modelagem de cenários preditivos de cobertura e uso do solo associada à produção agrícola e a logística de escoamento de cargas por ferrovias é algo ainda pouco explorado na literatura.

O planejamento de um projeto de infraestrutura em larga escala, além de estudos sobre os seus custos, benefícios e riscos, deve assegurar que o projeto apresente viabilidade e sustentabilidade econômica, técnica, social e ambiental, tanto da infraestrutura a ser construída quanto da região servida pela via. Todavia, um dos principais obstáculos para o planejamento é a ausência de estudos que apontem para tendências futuras quanto às transformações da cobertura e uso do solo, bem como das políticas públicas a ele aplicadas.

Neste sentido, o presente trabalho reporta um estudo desenvolvido para o MATOPIBA (SOUZA, 2017), região compreendida pelos estados do Maranhão, Tocantins, Piauí e Bahia. O MATOPIBA é considerado uma das novas fronteiras agrícolas brasileiras, aonde vem ocorrendo o aumento significativo da produção agropecuária, principalmente o cultivo de soja (HORVAT et al., 2015). Na perspectiva logística, a região apresenta distâncias menores para os portos exportadores e para o mercado consumidor nacional. Não obstante, a área é interceptada por três ferrovias, duas delas ainda inoperantes, o que tem elevado o interesse econômico pela intensificação da agricultura na região. Contudo, a questão a ser respondida é:o quanto das transformações na paisagem da região podem ser reflexo da infraestrutura ferroviária em desenvolvimento ou em planejamento?

Diniz (2006) mostra que, os novos programas de colonização agrícola e povoamento das regiões Norte e Nordeste do Brasil tiveram início com o governo do Presidente Getúlio Vargas entre os anos 1930 e1945. 
Este autor também mostra que a construção de Brasília selou a opção pela matriz rodoviária no Brasil, sendo o ponto nodal desta rede na então nova capital federal, o que, uma vez completa a infraestrutura de transporte terrestre, permitiria uma maior integração do Centro-Oeste com as demais regiões do país. O plano colocaria a região nos rumos da expansão agrícola. O Estado brasileiro, principalmente por meio da Empresa Brasileira de Pesquisa Agropecuária (EMBRAPA), como expõe EMBRAPA Cerrados (2008), colaborou no processo de intensificação da produção agrícola da região, desenvolvendo tecnologia e estudos para correção do solo e desenvolvimento de equipamentos e insumos para a exploração agropecuária. A região também foi foco de interesse do governo federal durante a primeira metade da década de 2010, com o extinto Plano de Desenvolvimento Agrário do MATOPIBA (BRASIL, 2015). Brasil (2011) projeta uma produção de grãos de mais de 16 milhões de toneladas para o biênio 2020/2021 na região do MATOPIBA, contra 13.341 milhões para o biênio 2010/2011, representando um aumento de 25\%. Com a pressão sem precedentes resultante da expansão agropecuária, o bioma Cerrado está sendo muito afetado.

Segundo Myers et al. (2000), a área original do bioma Cerrado ocupava aproximadamente $20 \%$ do território brasileiro, com uma extensão de mais de $1.783 .200 \mathrm{~km}^{2}$, enquanto que atualmente ocupa 356.630 $\mathrm{km}^{2}$ com apenas $22.000 \mathrm{~km}^{2}$ de áreas protegidas. Dentre os impactos negativos quanto a expansão das atividades agrícolas no Cerrado, EMBRAPA Cerrados (2008) aponta a degradação dos recursos hídricos e do solo bem como a perda da biodiversidade e a redução das áreas com a vegetação original.

A expansão da rede ferroviária brasileira reserva à região do MATOPIBA um papel de destaque. Por estar localizado na área central do Brasil, apresentando regiões com grande produção agropecuária, sobretudo graneleira, e com a configuração esperada no futuro para a rede ferroviária brasileira, se assemelhando a coluna dorsal estruturante conectando outras ferrovias (VALEC, 2015), é projetado um grande incremento na estrutura ferroviária da região, com a construção/conclusão das Ferrovias Norte-Sul, Transnordestina e de Integração Oeste-Leste (FIOL), além da Estrada de Ferro Carajás, já construída. Tais obras e as suas posteriores operacionalizações potencialmente trarão impactos para a região, afetando aspectos naturais, físicos e socioeconômicos.

Dado esse contexto, os objetivos do presente trabalho são:

- investigar, através de análises de dados geográficos, o papel das infraestruturas ferroviárias de transporte nas mudanças recentes de uso e cobertura do solo ocorridas em MATOPIBA;

- conhecer as variáveis explicativas e os padrões dos fenômenos de mudanças de uso e cobertura do solo;

- explorar cenários preditivos para o uso e cobertura do solo na região.

Para a contextualização temporal do trabalho e quantificação dos parâmetros de mudanças foi adotado o período compreendido entre os anos 2000 e 2012, período escolhido com base nos mapas de uso e cobertura do solo de IBGE (2016), que são resultados do projeto "Mudanças no uso e cobertura da Terra", desenvolvido com o objetivo monitorar as alterações na cobertura e uso da terra do Brasil a cada dois anos.

Neste período ocorreram intensos investimentos na agricultura dessa região, bem como o início da operação da ferrovia Norte-Sul e também a mobilização do Governo para construção das ferrovias Transnordestina e FIOL. Para entender e quantificar as transformações na paisagem foi desenvolvido uma modelagem espacial que propiciou o levantamento de algumas hipóteses sobre o papel dos trilhos, dos pátios ferroviários e dos terminais intermodais na dinâmica das mudanças do padrão de cobertura e uso de solo na região. Neste contexto, os principais tópicos levantados foram em relação à influência das infraestruturas ferroviárias na supressão de áreas naturais do bioma Cerrado e do avanço agropecuário na região.

Foi gerado um modelo que integrou 67 variáveis e foi calibrado para os anos de 2010 e 2012, período em que as transições de padrões de cobertura e uso de solo se intensificaram na região. A partir destes resultados foram produzidos dois cenários futuros distintos: um levando em conta as tendências já observadas na modelagem executada para uma previsão de uso do solo para os anos de 2017, 2020, 2030 e 2040 e o outro cenário dando maior ênfase às infraestruturas de transporte, como se todas estivessem já operacionais, para as mesmas datas.

\section{Caracterização da Área e dos Objetos de Estudo}

\subsection{Definição da Área de Estudos}

Foi utilizada como área de estudos a definição de Miranda et al. (2014), que considerou características físicas e humanas para a caracterização geográfica do MATOPIBA, levando em conta a localização das áreas do bioma Cerrado e os limites das microrregiões estaduais propostos pelo Instituto Brasileiro de Geografia e Estatística (IBGE). Para este trabalho, foram excluídas as microrregiões ao norte do Maranhão que estavam 
compreendidas pela Ferrovia Carajás, que não é objeto de estudo deste trabalho. Por fim, a Figura 1 mostra a área de estudos definida.

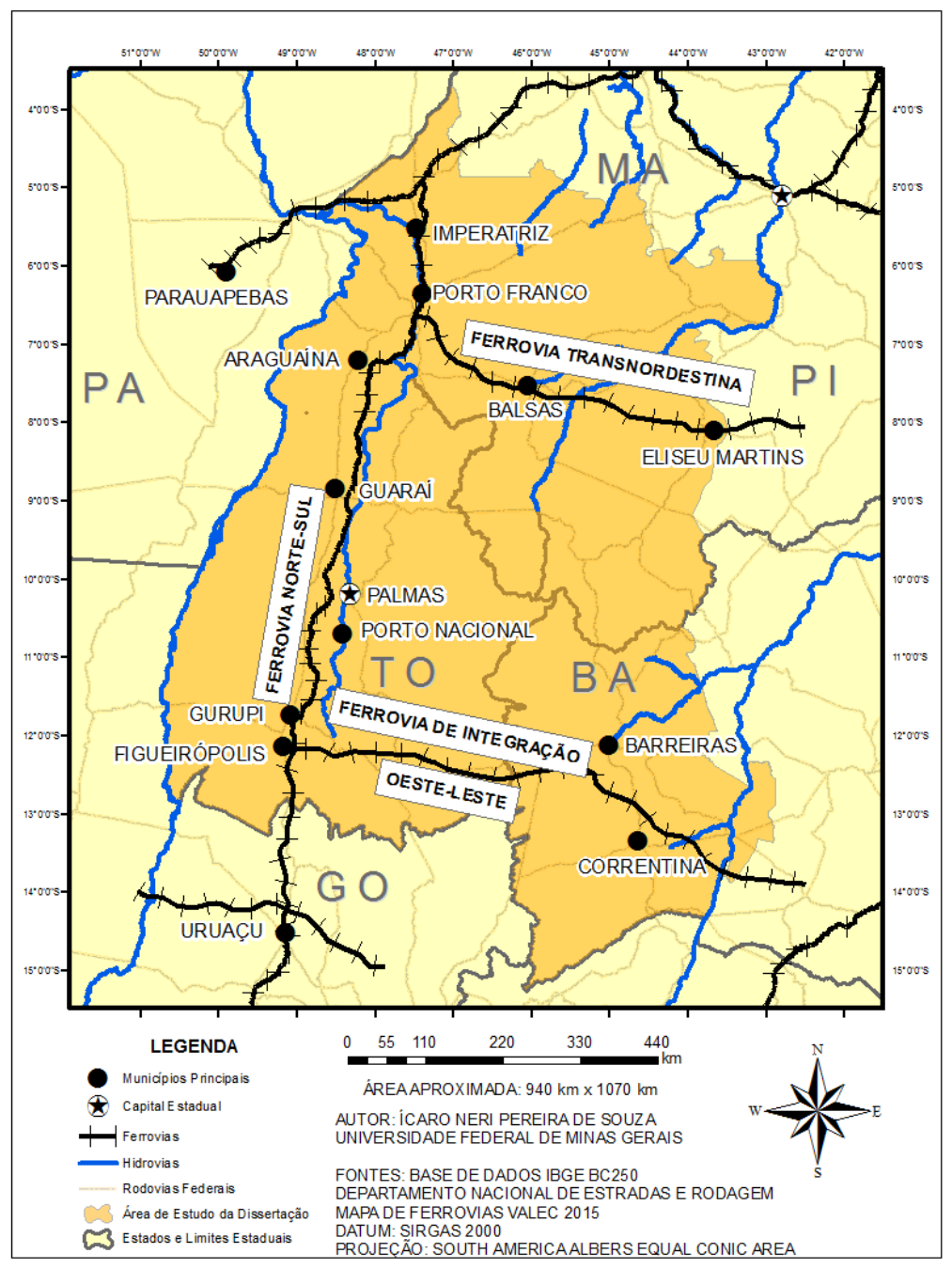

Figura 1: Ilustração da área de estudo formada pela confluência das ferrovias estruturantes Transnordestina, Norte-Sul e FIOL na região do MATOPIBA.

\subsection{Definição dos Objetos de Estudo}

$\mathrm{O}$ estudo, que investiga o papel da infraestrutura ferroviária nas mudanças da cobertura do solo no MATOPIBA, é caracterizado pelo entendimento das alterações na paisagem da região. Contudo, para compreender a dinâmica da paisagem é necessário quantificar as alterações no padrão de cobertura do solo, etapa que é desenvolvida a partir de métricas aplicadas às classes de uso e cobertura do solo, que são polígonos definidos por IBGE (2016), presentes na área de estudos. São elas:

- Área artificial: áreas com mais de 75\% do polígono ocupado com uso urbano, ou aldeias indígenas ou áreas de lavra de mineração.

- Área agrícola: áreas com mais de $75 \%$ do polígono ocupado por lavouras temporárias ou permanentes, em descanso ou plantadas.

- Pastagem com manejo: correspondem a áreas ocupadas por vegetação herbácea cultivada, destinadas ao pastoreio de gado e outros animais.

- Mosaico de áreas agrícolas com remanescentes florestais: áreas que apresentam entre 50\% e 75\% de ocupação com agricultura, pastagens e/ou silvicultura e o restante ocupado por remanescentes florestais.

- Silvicultura: áreas com mais de 75\% do polígono ocupado por silvicultura.

- Vegetação florestal: áreas com mais de 75\% do polígono ocupado por florestas.

- Mosaico de vegetação florestal com atividade agrícola: áreas que apresentam entre $50 \%$ e $75 \%$ do polígono ocupado por vegetação florestal e o restante ocupados por lavouras temporárias ou permanentes, pastagens e/ou silvicultura. 
- Vegetação campestre: áreas com mais de 75\% do polígono ocupado vegetações não-arbóreas.

- Pastagem natural: áreas ocupadas por vegetação campestre sujeitas a atividades antrópicas de baixa intensidade.

- Mosaico de áreas agrícolas com remanescentes campestres: áreas que apresentam entre 50\% e 75\% do polígono ocupado com agricultura, pastagens e/ou silvicultura e o restante formado por remanescentes campestres.

- Corpo d'água continental: engloba corpos d'água lineares, lagos e reservatórios.

- Áreas descobertas: englobam áreas com rochas expostas, blocos, detritos e terrenos abandonados.

\section{Metodologia da Pesquisa}

Foram quatro as etapas desenvolvidas na metodologia do trabalho, na ordem: Obtenção e préprocessamento dos dados de entrada; preparação das variáveis do modelo; modelagem espacialmente explícita e a geração de cenários e mapas analíticos.

\subsection{Coleta e Pré-Processamento dos Dados}

A etapa de obtenção dos dados corresponde aquisição dos dados geográficos de entrada no trabalho e o seu processamento em ambiente SIG, incluindo o recorte geográfico, padronizações cartográficas e formatação. Foi definido o Datum SIRGAS 2000 com projeção Cônica Equivalente de Albers, que integra toda a região de estudo em um plano, privilegiando minimizar distorções em área, a qual é objeto central para a quantificação das mudanças na paisagem. Os dados de entrada (mapas e tabelas) corresponderam a a índices socioeconômicos, infraestrutura, agropecuária, feições naturais, atividades econômicas e áreas de unidades de conservação (SNUC). Foram obtidos dados gratuitos, de fontes públicas e privadas, como a Base Cartográfica Contínua do Brasil na escala de 1:250.000 (BC 250) do IBGE; do Laboratório de Processamento de Imagens e Geoprocessamento (LAPIG), pertencente ao Instituto de Estudos Sócio Ambientais (LAPIG-IESA) da Universidade Federal de Goiás (UFG); da plataforma Geoweb Matopiba, da EMBRAPA; e do Centro de Sensoriamento Remoto da Universidade Federal de Minas Gerais (CSRUFMG).

Após a obtenção, todos os dados foram recortados para a área de estudo, e analisados quanto a integralidade, temporalidade e completitude das informações, sendo os dados duplicados e/ou redundantes descartados do modelo. Outra análise importante foi à relevância da informação quanto à influência da infraestrutura ferroviária, que permitiu, por exemplo, excluir informações de produtos agrícolas com baixa incidência e volume incompatível com o esperado para ser movimentado por trilhos. Todo o préprocessamento dos dados foi desenvolvido utilizando a plataforma Esri ArcGIS.

\subsection{Preparação das Variáveis do Modelo}

Essa etapa contou com a conversão dos dados previamente obtidos e já padronizados para o formato raster. Foi utilizada a resolução de pixel de 100 metros. Cabe ressaltar que a resolução espacial foi definida após sucessivos testes de desempenho do modelo com resoluções distintas (30m, 100m e 250m), com a finalidade de assegurar a operacionalidade do modelo sem o comprometimento da informação espacial.

Com o objetivo de transformar os dados previamente obtidos em variáveis de entrada para o modelo, convertendo dados discretos em contínuos (matriciais), essa etapa recorreu a técnicas de geoprocessamento como a interpolação (krigagem), densidade (kernel), distâncias euclidianas e cálculo da declividade, além de conversões simples de dados vetoriais (ponto, linha e polígono) para dados matriciais. Assim como a etapa anterior, esses processamentos se deram na plataforma Esri ArcGis.

\subsection{Modelagem Espacialmente Explícita}

A etapa de processamento e modelagem espacial dos dados em ambiente SIG foi desenvolvida na plataforma Dinamica EGO (SOARES-FILHO et al., 2004, 2009). Esta etapa buscou analisar os padrões de mudanças de cobertura do solo na área de estudo no MATOPIBA, e identificar as variáveis que influenciaram neste processo bem como o grau de influência de cada variável. 
Com base em Soares-Filho et al. (2009), foram estudados dois períodos distintos: período 2000-2010 e 20002012, utilizando os mapas de uso e cobertura do solo disponibilizados por IBGE (2016) disponíveis no momento de desenvolvimento do trabalho.

A primeira fase desta etapa consistiu na análise das matrizes de transição entre as classes de uso e cobertura do solo, de modo a quantificar as mudanças de classes ocorridas na área de estudos. Cabe ressaltar que a matriz de transição corresponde ao cálculo de probabilidade global de alterações possíveis da área de pesquisa, expressa em valores percentuais ou em área (BELL e HINOJOSA, 1977). A matriz de transição apresenta duas taxas: uma líquida, que representa as mudanças totais entre as classes de cobertura do solo para o período analisado e uma bruta, especificada por unidade de área para um passo de tempo, no caso, ano a ano (SOARES-FILHO et al., 2009).

Com as matrizes de transição calculadas e considerando também as variáveis modeladas anteriormente, foi calculada a participação de cada uma destas variáveis em cada uma das mudanças de classe, utilizando o cálculo de "pesos de evidência" (GOODACRE et al., 1993; BONHAM-CARTER, 1994). Partindo da premissa que todas as variáveis são independentes umas das outras, o método de pesos de evidência é um método bayesiano que estima a probabilidade de uma transição no uso do solo (por exemplo de floresta para não floresta) a partir do contexto espacial (por exemplo distância a rodovias, proximidade de áreas desmatadas) (SOARES-FILHO et al, 2009). Singer e Kouda (1999) afirmam que a proposta do método de pesos de evidência é produzir mapas mostrando a probabilidade de ocorrência de um fenômeno espacial e a incerteza associada das probabilidades estimadas. Essa é uma análise na escala local, na unidade do pixel, sendo a etapa de parametrização da probabilidade local de alteração de uso.

Soares-Filho et al. (2009) descreve a fórmula de pesos de evidência quando existem mais de uma variável a ser analisada como possível evidência de uma transição de classes de uso e cobertura do solo:

$$
P\{i \rightarrow j \mid B \cap C \cap D \ldots \cap N\}=\frac{e^{\sum w_{N}}}{1+e^{\sum w_{N}}}
$$

Onde: $\mathrm{i}=>\mathrm{j}$ é uma mudança de uso e cobertura do solo, sendo i e j classes, e B,C,D o conjunto de variáveis explicativas a serem medidos na localização $\mathrm{x}$,y e representados pelo seu peso $W+{ }^{N}$ Valores positivos para as classes da variável tendem a estar associados com transições enquanto valores negativos tendem a repelir a transição estudada.

Segundo Soares-Filho (et al., 2004) o peso de evidência de uma variável numa transição representa a influência de cada faixa de valores (num processo de discretização de valores contínuos) de certa variável (como por exemplo, a distância para uma variável, o tipo de solo e etc.) nas probabilidades espaciais de transição. Pode se analisar, por exemplo, a influência da distância para um pátio ferroviário na mudança de classe de vegetação florestal para uso agrícola.

\subsection{Geração de Cenários e Mapas Analíticos}

Após esta etapa, foram geradas simulações de mudanças do padrão de cobertura do solo utilizando como base o mapa de uso e cobertura do solo de IBGE (2016) do ano 2000 para os anos 2010 e 2012. Essa simulação foi produzida utilizando a geração de manchas pixel a pixel a partir das transições de mudanças de classes de uso e cobertura do solo utilizando os operadores Patcher e Expander presentes no software DINAMICA EGO. O primeiro processo foi criado para gerar ou formar novas manchas de uma classe utilizando um mecanismo de semeadura, onde um local de transição de classe é selecionado e "manchas" são geradas no seu entorno, representando a classe final do processo de transição. O segundo é dedicado somente para expandir ou contrair manchas de certa classe (SOARES-FILHO et al., 2009). O conceito geográfico de mancha (patch) é oriundo da ecologia da paisagem (FORMAN, 1995; MCGARICAL et al., 1995).

Após a fase da simulação o modelo foi então calibrado para reduzir as diferenças entre os mapas reais observados e os mapas simulados. Para calibrar um modelo pode se, por exemplo, alterar, adicionar ou excluir as variáveis utilizadas na etapa de obtenção e pré-processamento e modificar os pesos de evidência gerados anteriormente pelo software DINAMICA EGO, por exemplo, com base no que foi verificado na literatura em relação ao comportamento das transições de classe. Detalhes sobre a calibração do modelo e edição das faixas de discretização e dos pesos de evidência podem ser acessados em Souza (2017).

Juntamente com a etapa de calibração é feita a validação da modelagem. Esta etapa verifica a locação espacial das mudanças, onde utilizando a lógica Fuzzy (HAGEN, 2003) calcula-se a similaridade entre os 
mapas reais e simulados. Desta forma, são gerados os mapas de similaridade de mudanças. Na sequência, utilizando a função de decaimento exponencial, foi calculado o grau de acerto, processo que utilizou janelas com configurações de pixels de $1 \times 1,3 \times 3,5 \times 5,7 \times 7$ e 9x9.

Após a validação, foram gerados mapas simulando o uso e cobertura do solo futuros para os anos 2017, 2020, 2030 e 2040. Foram considerados dois cenários distintos nas simulações: um observando as tendências verificadas na modelagem e outro com os pesos de evidência editados para dar maior ênfase ao papel das infraestruturas ferroviárias de transporte nas mudanças de uso e cobertura do solo, simulando condições de operacionalidade (simulando uma maior atração da atividade agropecuária para o entorno dos pátios ferroviários, terminais intermodais e estradas de acesso à rede ferroviária). Assim, as principais tendências e diferenças entre ambos foram analisadas de forma a levantar hipóteses quanto ao papel das infraestruturas ferroviárias de transporte nessas dinâmicas.

\section{Resultados e Discussões}

\subsection{Matrizes de Transições de Mudanças de Uso e Cobertura do Solo}

No geral, para o período 2000-2012 foi observado uma diminuição das áreas com vegetação natural na área de estudo e um avanço das áreas com atividade agrícola. A classe de uso do solo que mais perdeu área foi "pastagem natural", seguida pela classe "vegetação campestre". Ambas as classes estão inseridas bioma Cerrado. As áreas que mais ganharam área percentualmente foram aquelas classificadas como "área agrícola", "pastagem com manejo" e também áreas classificadas como "mosaico de área agrícola com remanescentes campestres".

As matrizes de transições geradas mostram que ocorreram mais mudanças de uso e cobertura do solo no sentido da expansão agropecuária e retração do bioma Cerrado no período de 2010-2012 do que no período 2000-2010. A Tabela 1 mostra as mudanças principais de classe observadas na área de estudos para os períodos 2000-2010, 2000-2012 e 2010-2012, enquanto a Tabela 2 mostra, em quilômetros quadrados, as áreas de cada classe de uso e cobertura do solo na área de estudo.

Com base nas transições calculadas para as classes de cobertura do solo foram desenvolvidas as modelagens espacialmente explícitas para os períodos 2000-2010 e 2000-2012. Dadas as diferenças descritas nas transições, percebe-se que houve um aumento percentual da expansão da atividade agrícola no período 2010-2012 em relação ao período 2000-2010. Detalhes sobre as taxas anuais de variação podem ser acessados em Souza (2017).

Tabela 1: Principais transições de uso do solo por tamanho e porcentagem de área no MATOPIBA.

\begin{tabular}{|c|c|c|c|c|c|}
\hline $\mathrm{De}^{*}$ & Para* & $($ Área km²) 2000-2010 & $($ Área km²) 2000-2012 & $($ Área km²) 2010-2012 & $\% 2000-2012$ \\
\hline 10 & 2 & $13.915,83$ & $25.853,31$ & $1.1937,48$ & $5,72 \%$ \\
\hline 10 & 3 & $16.084,54$ & $22.777,93$ & $6.693,39$ & $5,04 \%$ \\
\hline 10 & 11 & $2.620,51$ & $9.711,03$ & $7.090,52$ & $2,15 \%$ \\
\hline 7 & 4 & $1.596,24$ & $5.227,58$ & $3.631,34$ & $10,32 \%$ \\
\hline 7 & 3 & $3.324,23$ & $4.833,67$ & $1.509,44$ & $9,54 \%$ \\
\hline 6 & 3 & $1.898,92$ & $2.145,37$ & 246,45 & $9,98 \%$ \\
\hline 6 & 7 & $1.791,39$ & $1.932,33$ & 140,94 & $8,99 \%$ \\
\hline 8 & 10 & $1.055,66$ & $1.792,89$ & 737,23 & $20,09 \%$ \\
\hline 4 & 3 & 776,66 & $1.452,05$ & 675,39 & $5,76 \%$ \\
\hline 6 & 4 & $1.094,62$ & $1.081,25$ & $-13,37$ & $5,03 \%$ \\
\hline 4 & 2 & 405,98 & 632,73 & 226,75 & $2,51 \%$ \\
\hline 7 & 2 & 207,76 & 530,27 & 322,51 & $1,05 \%$ \\
\hline 10 & 1 & 180,73 & 190,56 & 9,83 & $0,04 \%$ \\
\hline 6 & 2 & 124,73 & 173,63 & 48,90 & $0,81 \%$ \\
\hline
\end{tabular}

Legenda: 1- Área Artificial, 2- Área Agrícola, 3- Pastagem com Manejo, 4- Mosaico de Áreas Agrícolas com Remanescentes Florestais, 5- Silvicultura, 6- Vegetação Florestal, 7- Mosaico de Vegetação Florestal com Atividade Agrícola, 8- Vegetação Campestre, 10- Pastagem Natural, 11- Mosaico de Áreas Agrícolas com Remanescentes Campestres 
Tabela 2: Tamanho das áreas em quilômetros quadrados das classes de uso e cobertura do solo na área de estudos para os anos de 2000, 2010 e 2012.

\begin{tabular}{cccccc}
\hline Classe & $\left(\mathbf{A} \mathbf{r e a ~} \mathbf{K m}^{2}\right) \mathbf{2 0 0 0}$ & $\left(\mathbf{A} \mathbf{r} \mathbf{~} \mathbf{K m}^{2}\right) \mathbf{2 0 1 0}$ & $\left(\mathbf{A} \mathbf{r e a ~} \mathbf{K m}^{2}\right) \mathbf{2 0 1 2}$ & Diferença 2000-2012 & \% 2000-2012 \\
\hline 1 & 874,27 & $1.047,38$ & $1.063,57$ & 189,3 & $21,65 \%$ \\
2 & $28.677,63$ & $43.366,29$ & $56.118,9$ & $27.441,27$ & $95,69 \%$ \\
3 & $42.632,36$ & $64.615,57$ & $73.727,3$ & $31.094,94$ & $72,94 \%$ \\
4 & $25.216,24$ & $26.780,22$ & $29.399,1$ & $4.182,86$ & $16,59 \%$ \\
5 & 392,41 & 340,78 & 367,55 & $-24,86$ & $-6,34 \%$ \\
6 & $21.505,34$ & $16.584,33$ & $16.160,1$ & $-5.345,24$ & $-24,86 \%$ \\
7 & $50.674,19$ & $47.446,74$ & $42.036,5$ & $-8.637,69$ & $-17,05 \%$ \\
8 & $8.923,58$ & $7.865,82$ & $7.111,29$ & $-1.812,29$ & $-20,31 \%$ \\
9 & 20,45 & 20,45 & 20,45 & 0 & $0,00 \%$ \\
10 & $451.812,81$ & $420.037,21$ & 395.020 & $-56.792,81$ & $-12,57 \%$ \\
11 & $11.823,8$ & $14.421,31$ & $21.502,1$ & $9.678,3$ & $81,85 \%$ \\
12 & $7.188,67$ & $7.188,67$ & $7.188,67$ & 0 & $0,00 \%$ \\
14 & 940,82 & 967,8 & 967,54 & 26,72 & $2,84 \%$ \\
\hline
\end{tabular}

Legenda: 1- Área Artificial, 2- Área Agrícola, 3- Pastagem com Manejo, 4- Mosaico de Áreas Agrícolas com Remanescentes Florestais, 5- Silvicultura, 6- Vegetação Florestal, 7- Mosaico de Vegetação Florestal com Atividade Agrícola, 8- Vegetação Campestre, 10- Pastagem Natural, 11- Mosaico de Áreas Agrícolas com Remanescentes Campestres, 12- Corpo d'água Continental, 14- Âreas Descobertas

\subsection{Análises dos Pesos das Variáveis nas Transições de Classes pelo Método Pesos de Evidência}

Após as análises das transições, foram feitas as análises relativas aos pesos das classes de cada variável nas principais transições de uso e cobertura do solo na área de estudos. Foram selecionadas para estas análises as transições que afetaram mais de $100 \mathrm{~km}^{2}$ de área, além de todas as outras que afetaram áreas menores, mas que correspondem às principais dinâmicas espaciais observadas: o avanço das áreas agrícolas e a retração das áreas do bioma Cerrado.

Quanto ao papel das variáveis investigadas foram verificados que as áreas cobertas pelo Sistema Nacional de Unidades de Conservação (SNUC) tendem a repelir expansão agropecuária favorecendo a preservação das áreas naturais: as variáveis "estação ecológica", "refúgio da vida silvestre" e "terras indígenas" praticamente repulsaram todas as transições no sentido da expansão agropecuária e a variável "parque nacional" também teve peso negativo para a maioria destas transições. As áreas que mais se destacam nessa dinâmica são a Estação Ecológica Serra Geral do Tocantins e as Terras Indígenas Arariboia e Cana Brava/Guajajara, no Maranhão.

As variáveis que também tendem a repulsar as mudanças de uso e cobertura do solo no sentido da expansão agropecuária: as linhas de transmissão futuras e a declividade elevada. No modelo calibrado as variáveis "aeródromos com asfalto concluído" e "população rural baixa" também apresentaram forte repulsão. As variáveis "altitude elevada", "produção de soja por município em tonelada" e "áreas de queimada por município" reprimiram algumas mudanças de uso e cobertura do solo para a o uso agropecuário, porém estas variáveis atraíram a transição de pastagem natural para áreas agrícolas.

Quanto à atratividade destas mudanças, apresentaram probabilidade de atração a uma intensificação das atividades agrícolas as variáveis relativas às propriedades rurais e áreas de pastagem. Também apresentaram probabilidade às mudanças com cunho intensificador da produção agropecuária as variáveis "aptidão para a cultura de soja" (nível alto), "áreas urbanas", "áreas de pastagem", "produção de banana", "floresta plantada" e "produção de mandioca". Em ambos os modelos, a categoria "chapadas e platôs" da variável "relevo", correspondente a altitudes elevadas, apresentou boa probabilidade para a transição de classes de "pastagem natural" para "área agrícola".

Em relação ao papel das infraestruturas ferroviárias de transporte, a Ferrovia FIOL, que não existe atualmente, mas está com o Estudo de Viabilidade Técnica, Econômica e Ambiental (EVTEA) concluído (VALEC, 2015), apresentou pesos iguais para a transição da classe "vegetação florestal" as classes "mosaico de vegetação florestal com atividade agrícola" (muito forte até $8 \mathrm{~km}$, com atração até $50 \mathrm{~km}$ ), "mosaico de área agrícola com remanescentes florestais" (muito forte até $200 \mathrm{~m}$, com atração até $50 \mathrm{~km}$ ), "pastagem com manejo" (muito forte até $1,6 \mathrm{~km}$, com atração até $50 \mathrm{~km}$ ) e "área agrícola" (muito forte até $11 \mathrm{~km}$, com atração até $50 \mathrm{~km}$ ). Também foi observada atração para a transição da classe "pastagem natural" para as classes "área agrícola" e "pastagem com manejo". 
Quanto à Ferrovia Norte-Sul, a única existente na área de estudos, esta apresentou peso de retração da classe "vegetação florestal" até em $100 \mathrm{~km}$, enquanto que não houve grande influência para a expansão da atividade agropecuária.

A Ferrovia Transnordestina, que assim como a Ferrovia FIOL não existe atualmente, mas que apresenta o EVTEA concluído teve o seu traçado apresentando probabilidade para a retração da classe "vegetação florestal" em detrimento das classes "pastagem com manejo", "mosaico de áreas agrícolas com remanescentes florestais" e "mosaico de vegetação florestal com atividade agrícola". A modelagem revelou probabilidade de mudanças de transição de "vegetação campestre" para "área agrícola", influenciadas pelo traçado da Ferrovia Transnordestina (variando de muito forte até a faixa de $20 \mathrm{~km}$, atingindo até $73 \mathrm{~km}$ ).

Os terminais intermodais, que futuramente, na área de estudos, irão se concentrar no eixo da Ferrovia FIOL (VALEC, 2015), apresentou peso de atração para a transição de classe de "vegetação florestal" para "área agrícola" e "pastagem com manejo". Além dessas duas transições, ainda houve peso forte para as transições de "vegetação florestal" para "mosaico de área agrícola com remanescentes campestres" e "mosaico de vegetação florestal com atividade agrícola" (com peso forte em até $50 \mathrm{~km}$ e $100 \mathrm{~km}$, respectivamente).

Por fim, os pátios ferroviários da Ferrovia Norte-Sul apresentaram peso significativo para a retração da classe "vegetação florestal" em detrimento das classes "pastagem com manejo" (forte até $500 \mathrm{~m}$ com influência até $86 \mathrm{~km}$ ) e "mosaico de área agrícola com remanescentes florestais" (com forte influência até $100 \mathrm{~m}$ e com influência até $85 \mathrm{~km}$ ). Foi verificado também forte influencia para as transições de "vegetação florestal" para "área agrícola" (até $4 \mathrm{~km}$, finalizando em $36 \mathrm{~km}$ ) e "pastagem natural" para "área agrícola" (forte até $48 \mathrm{~km}$, total até $82 \mathrm{~km}$ ).

\subsection{Simulações $e$ Validações}

Com os pesos de evidência e as transições analisadas foram então feitas as validações e as simulações futuras. Também foram realizados ensaios com os pesos de evidência editados afim de simular um papel das infraestruturas ferroviárias de transporte em todas as transições de classe com área afetada acima de $100 \mathrm{~km}^{2}$ e todas abaixo destas que representavam uma intensificação das atividades agropecuárias. A edição dos pesos de evidência foi intencional no sentido de provocar no modelo a reação a uma hipotética reconfiguração das atividades de expansão agropecuária contextualmente às infraestruturas ferroviárias de transporte, sobretudo aos pátios ferroviários e terminais intermodais (que servem como pontos de acesso e saída da rede). Esse ensaio corresponde a uma das hipóteses descritas no trabalho de Souza (2017).

Foi verificado um padrão de expansão agropecuária muito mais forte no período 2010-2012 do que no período 2000-2010, mostrando que no intervalo 2010-2012 o ritmo dessa dinâmica se intensificou. Foi verificado também que as validações feitas no modelo com os pesos de evidência editados tiveram índices de acerto semelhantes ao modelo sem a edição dos pesos, porém com uma readequação espacial das mudanças, para o entorno das áreas onde estas infraestruturas estão presentes, deixando áreas mais distantes protegidas destas transições. Os resultados mostram que os modelos com os pesos de evidência editados tiveram acertos bons, mostrando que o traçado das infraestruturas ferroviárias de transporte, mesmo que algumas ainda não existentes apresentaram boa correlação com as transições que representam uma expansão da atividade agropecuária. A Figura 2 mostra as simulações produzidas nessa etapa: 


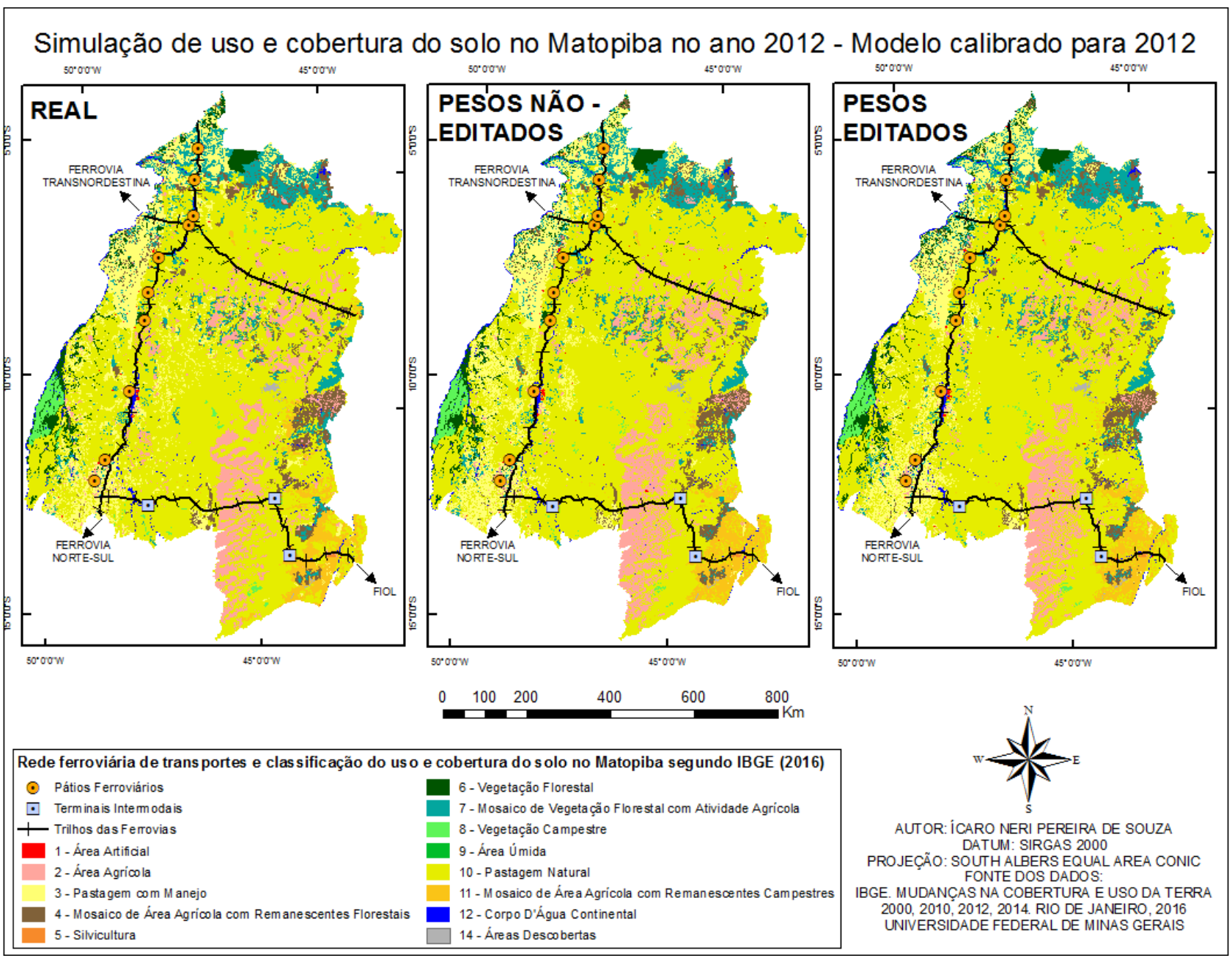

Figura 2: Simulação do uso e cobertura do solo no Matopiba no ano 2012 - Modelo calibrado para o ano 2012.

A validação por múltiplas janelas apresentou $47 \%$ de similaridade sem a edição dos pesos, com $45 \%$ de acertos na similaridade total em relação ao mapa real, enquanto que o modelo com os pesos editados apresentou $45 \%$ de acerto com $44 \%$ de acertos na similaridade total em relação ao mapa real. O mesmo modelo, quando simulado e validado para o ano 2010, apresentou $28 \%$ de similaridade sem a edição dos pesos de evidência e $26 \%$ com a edição, com $27,5 \%$ e $25,5 \%$ de similaridade total em relação ao mapa real deste ano.

\subsection{Simulações Futuras para 2040}

Com as validações concluídas, foram produzidos cenários simulados, sem e com a edição dos pesos de evidência dando ênfase para o papel das infraestruturas de transporte, para os anos 2017, 2020, 2030 e 2040. Foram verificadas tendências de readequação da localização das atividades agrícolas em torno das infraestruturas ferroviárias de transportes, porém as principais mudanças apuradas foram em relação à dimensão espacial das classes de cobertura do solo.

No geral, até o ano 2030, as classes geradas relativas à produção agropecuária foram menores na simulação com os pesos editados em relação ao tamanho das mesmas classes geradas na simulação sem os pesos editados. Nos mapas gerados para o ano 2040 o tamanho das classes de uso e cobertura do solo praticamente se igualou, com um processo de readequação espacial houve um fonte incremento no tamanho das classes relativas à produção agropecuária quando comparado com os mapas gerados para o ano 2030.

A Figura 3 mostra os mapas gerados para o ano 2040, com e sem a edição dos pesos de evidência, no modelo calibrado para 2012. 


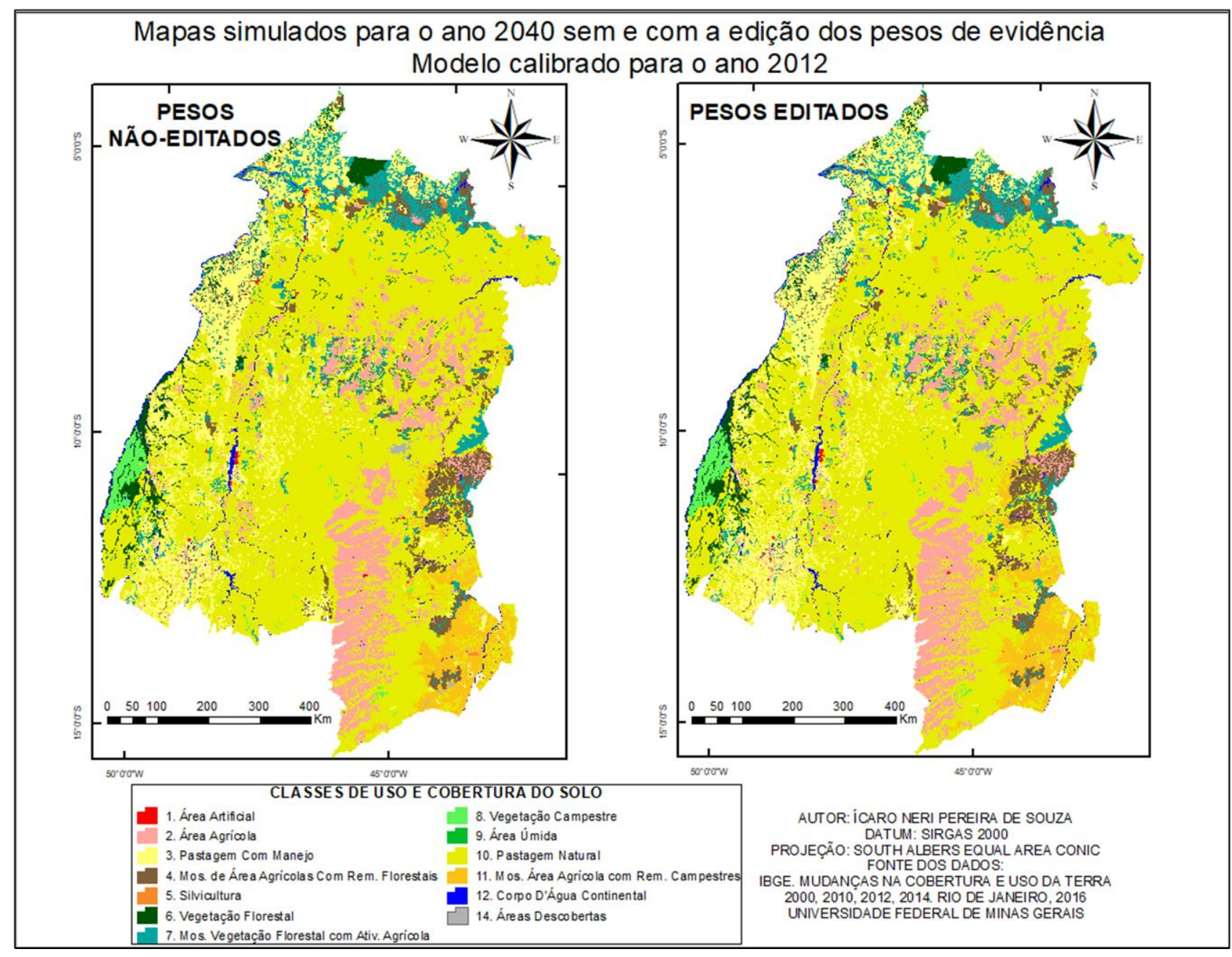

Figura 3: Mapas simulados para o ano 2040 sem e com a edição dos pesos de evidência - Modelo calibrado para o ano 2012

\section{Conclusões}

Este trabalho investigou os determinantes espaciais que tendem a estimular as transições de uso e cobertura do solo na área de MATOPIBA no período 2000 a 2012 dando particular enfoque ao papel que as infraestruturas ferroviárias atuais e projetadas podem ter nessas mudanças. Para tanto, foram desenvolvidas análises simulando cenários de operação da malha ferroviária na região, composta pelas Ferrovias Norte-Sul, Fiol, Transnordestina e seus pátios e terminais ferroviários, afim de testar a hipótese de que a operacionalidade das infraestruturas ferroviárias pode estimular uma maior expansão agrícola na região.

Esses resultados demonstram que as infraestruturas ferroviárias de transporte podem sim ser indutoras da expansão agropecuária no MATOPIBA. As métricas obtidas demonstram que, muitas transições entre as classes de uso e cobertura do solo, principalmente no que diz respeito à retração da vegetação em prol da expansão agropecuária, os modais ferroviários, existentes ou não, apresentaram pesos fortes e consideráveis com probabilidade de atrair estas transições.

A metodologia adotada utilizou a análise dos pesos de evidencia, que se baseiam em estimar pesos às classes das variáveis tendo o conhecimento prévio da ocorrência (ou não) de um determinado fenômeno na presença ou ausência dessa variável gerando um mapa de probabilidade das transições. Contudo, este método, por si só não é capaz de responder a questões tão complexas, posto que estima quais são os determinantes espaciais (por exemplo, estar perto ou distante das rodovias ou dos pátios ferroviários) e suas contribuições para as transições entre as classes de uso e cobertura do solo. Desta forma, a estratégia usada foi deixar com que o sistema calculasse os pesos de evidência das probabilidades de transições de classes para que, em um segundo momento estes fossem modificados criando cenários simulados. 
Os resultados do trabalho, analisado para os períodos entre 2000-2010 e entre 2000-2012, mostram claramente a supressão de áreas de cerrado, resultados esses que corroboram os resultados encontrados no trabalho de Lima (2014). O aumento da expansão agropecuária no período 2010-2012 em relação ao período 2000-2010 foi tão contundente que foram desenvolvidos cenários conservador e intensivo da expansão agropecuária explorando as diferenças de uso e cobertura do solo verificada nos períodos 2000-2010 e 20002012.

O uso de modelos matemáticos, econométricos e espaciais ajudam a entender as complexas dinâmicas físicas e humanas e as suas relações que ocorrem na realidade e tem cada vez mais uma crescente demanda por parte dos tomadores de decisão. Mesmo sendo uma metodologia robusta, a modelagem espacialmente explícita depende de ponderações e responde com limitações a estas questões complexas comumente envolvidas no entendimento e nas soluções de problemas em sistemas ambientais. As próprias ponderações ao uso do método dos pesos de evidência é uma reflexão quanto a isso. Para além de tudo isto, sempre haverá incertezas relativas aos modelos devido à impossibilidade de se transformar tudo que pode ser analisado no mundo em variáveis explicativas em um modelo, que é uma representação limitada da realidade. É louvável e recomendável o uso de modelos para análises da realidade e para o planejamento, porém estes poderão ser mais bem analisados quando utilizados como ferramentas e métodos, e não como o resultado final em si.

O mérito do presente estudo foi identificar a sinergia, ainda latente, entre questões relacionadas ao planejamento estratégico nacional quanto à implantação de ferrovias estruturantes e o potencial gatilho que estas promoverão na aceleração das mudanças na paisagem. Embora de grande valor para o desenvolvimento econômico regional e a macrologística, o emprego de técnicas de modelagem geográfica preditiva no planejamento de transportes em escala regional e nacional é ainda incipiente, fato que potencializa o caráter inovador deste estudo.

As melhorias futuras da modelagem deste trabalho devem incluir o constante aperfeiçoamento das variáveis usadas no modelo, sempre tentando representar melhor a realidade dado o contexto de cada época e até mesmo para pontuar as diferenças em relação aos períodos anteriores, além de contar com a atualização dos mapas de referência para o uso e cobertura do solo, disponibilizados por IBGE (2016). Também é recomendado o aperfeiçoamento da metodologia e o estudo de modelos que estudem as dinâmicas relativas à expansão agropecuária, ao bioma cerrado e às infraestruturas de transporte.

\section{Agradecimentos}

Os autores agradecem à Capes e ao CNPq pelo apoio ao desenvolvimento da pesquisa.

\section{Referências}

ARAUJO, F. R. N.; ALMEIDA, J. W. L.; SENA, I. S.; NOBREGA, R.A.A. Modelagem de corredores ótimos para instalação de empreendimentos ferroviários com o software livre Dinâmica EGO a partir de produtos gratuitos de sensoriamento remoto. In: XVII Simpósio Brasileiro de Sensoriamento Remoto, 2015, João Pessoa. Anais XVII Simpósio Brasileiro de Sensoriamento Remoto. São José dos Campos: Instituto nacional de Pesquisas Espaciais, 2015. v. 1. p. 3549-3556

BELL, E. J.; HINOJOSA, R. C. Markov analysis of land use change: continuous time and stationary processes. Socio-Economic Planning Sciences, v. 11, n. 1, p. 13-17, 1977.

BONHAM-CARTER, G. Geographic information systems for geoscientists: modeling with GIS. New York: Pergamon, 1994. 398 p.

BRASIL. Ministério da Agricultura, Pecuária e Abastecimento. Brasil Projeções do Agronegócio 2010/2011 a 2020/2021. Brasília, jun. 2011, 59p.

BRASIL. Decreto n ${ }^{\circ}$ 8.447, de 6 de maio de 2015. Dispõe sobre o Plano de Desenvolvimento Agropecuário do Matopiba e a criação do seu Comitê Gestor. Diário Oficial da União, Brasília, DF, n.85, p. 2, 6 mai. 2015. Seção 1, Parte 1. 2015

DINIZ, B. P. C. O grande Cerrado do Brasil Central: geopolítica e economia. 2006. 231 f. Tese (Doutorado). Universidade de São Paulo. 2006 
EMBRAPA CERRADOS. IV Plano Diretor da Embrapa Cerrados 2008 - 2011 - 2023 / Embrapa Cerrados - Planaltina, DF: Embrapa Cerrados, 2008. 42 p.

FORMAN, R. et al. Road ecology: science and solutions. [S.L.]: Island Press, 2003. 504 p.

FORMAN, R. T. T. Some general principles of landscape and regional ecology. Landscape Ecology, 10, 133-142 (1995).

GOODACRE, A.; BONHAM-CARTER, G. F.; AGTERBERG, F. P.; WRIGHT, D. F. A statistical analysis of the spatial association of seismicity with drainage patterns and magnetic anomalies in western Quebec: Tectonophysics, v. 217, no. 3-4, 1993. p. 285-305.

HAGEN, A. Fuzzy set approach to assessing similarity of categorical maps. International Journey of Geographical Information Science, v 17. n. 3. p. 235-249, 2003.

HAN, H; YANG, C; SONG, J. Scenario Simulation and the Prediction of Land Use and Land Cover Change in Beijing, China. Sustainability, [S.L], n. 7, p. 4260-4279, abr. 2014.

HORVAT, R.; WATANEBE, M.; YAMAGUCHI, C. K. Fertilizer consumption in the region of MATOPIBA and their reflections on Brazilian soybean production. International Journal of Agriculture and Forestry, v 5, n.1, p. 52-59. 2015

IBGE - Instituto Brasileiro de Geografia e Estatística. Mudanças na Cobertura e Uso da Terra 2000 2010 - 2012 - 2014. Rio de Janeiro, 2016. 33p

IBISCH, P. L. et al. A global map of roadless areas and their conservation status. Science, [S.L], v. 354, p. 1423-1427, dez. 2016.

KARLSON, M. et al. Design and evaluation of railway corridors based on spatial ecological and geological criteria. Transportation Research Part D: Transport and Environment, [S.L], v. 46, p. 207-228, jul. 2016.

KEELING, D. J. Transportation geography: new directions on well-worn trails. Progress in Human Geography, 31, 217-225. 2007.

LAPOLA, D. M. et al. Pervasive transition of the Brazilian land-use system. Nature climate change, [S.L.], v. 4, p. 27-35, jan. 2014. V. 2, n. 43, p.2-12, 2018.

LIMA, T. C. Modelagem dos vetores de mudança na paisagem no bioma cerrado. 2014. $56 \mathrm{f}$. Dissertação (Mestrado). Universidade Federal de Minas Gerais, Instituto de Geociências. 2014.

LIMA, T. C.; LIMA, G. M. C.; FREITAS, OLIVEIRA. M.S.; SOARES-FILHO. B.; DINAMICA EGO e Land Change Modeler para simulação de desmatamento na Amazônia brasileira: análise comparativa. In: Simpósio Brasileiro de Sensoriamento Remoto (SBSR), 16., 2013, Foz do Iguaçu. Anais. São José dos Campos: INPE, 2013. disponível em: <http://www.dsr.inpe.br/sbsr2013/files/p0471.pdf >. Acesso em: 03 mar. 2017.

MAES, J.; VANELSLANDER, T. The use of rail transport as part of the supply chain in an urban logistics context. In: WCTR Conference, 12, 11-15 July 2010, Lisbon.

MCGARIGAL, K.; MARKS, B. J. FRAGSTATS: spatial pattern analysis program for quantifying landscape structure. Gen. Tech. Rep. PNW-GTR-351. Portland, OR: U.S. Department of Agriculture, Forest Service, Pacific Northwest Research Station. 122 p. 1995.

MIRANDA, E. E.; MAgAlhães, L. A.; CARVAlho, C. A. Nota Técnica 1: Proposta de delimitação territorial do Matopiba. GITE EMBRAPA, Campinas, mai. 2014. Disponível em: <https://www.embrapa.br/gite/publicacoes/NT1_DelimitacaoMatopiba.pdf>. Acesso em: 03 mar. 2017.

MYERS, N.; MITTERMEIER, R. A.; MITTERMEIER, C. G.; FONSECA, G. A. B.; KENT, J. Biodiversity hotspots for conservation priorities. Nature, v. 403, p. 853-858, fev. 2000. 
NOBREGA, R. A. A.; VIEIRA, R. R. T.; BERBERIAN, C. F. Q.; MASUKAWA, N.; QUADROS, E. A. T. Inteligência geográfica para avaliação de propostas de projeto de concessão de corredores ferroviários. Transportes, Rio de Janeiro, v. 24, p. 75-84, 2016.

NOBREGA, R. A. A.; O`HARA, C. G.; SADASIVUNI, R.; STICH, B. M.. Assessing EnvironmentalImpacted Features of EIA Study in Corridor Planning Based on GIS and Remote Sensing Technologies. In: Simpósio Brasileiro de Ciências Geodésicas e Tecnologias da Geoinformação, 4, [s. 1.], mai. 2012. Anais do IV SIMGEO, Recife, p. 1-8.

NOBREGA, R. A. A.; STICH, B. Towards the Long Term Recovery in Mississippi: Understanding the Impact of Transportation System for Economic Resilience. Journal of Leadership and Management., v. 12, p. 21-35, 2012.

OLIVEIRA, L.K.; SANTOS, O.R.; OLIVEIRA, R.L.M.; NOBREGA, R.A.A. Is the location of warehouses changing in the Belo Horizonte Metropolitan Area (Brazil)? A logistic sprawl analysis in a Latin American context. Urban Science, v.2, n. 43, p. 1-12.2018.

SILVEIRA, M. R. A importância geoeconômica das estradas de ferro no Brasil. 2003. 454 f. Tese (Doutorado em Geografia). Universidade Estadual Paulista (UNESP), Presidente Prudente, 2003.

SINGER, D. A., KOUDA, R., 1999, A comparison of weights-of evidence methods and probabilistic neural networks. Natural Resources Research, v. 8, no. 4, p. 287-298

SOARES-FILHO, B.S.; RODRIGUES, H., COSTA, W. Modeling Environmental Dynamics with Dinamica EGO. Centro de Sensoriamento Remoto (IGC/ UFMG) - Universidade Federal de Minas Gerais, Belo Horizonte, MG, Brasil. 2009. Disponível em. http:// www.csr.ufmg.br/dinamica/ tutorial/ Dinamica_EGO_guidebook.pdf. Acesso em: 03.03.2017

SOARES-FILHO B.S., CERQUEIRA, G.C., ARAUJO, W. L., VOLL, E. Modelagem de dinâmica de paisagem: concepção e potencial de aplicação de modelos de simulação baseados em autômato celular. In: Ferramentas para modelagem da distribuição de espécies em ambientes tropicais. Albernaz A.L., Silva J.M.C. da, Valeriano, D.(editores) Editora Museu Paraense Emílio. 2004.

SOUZA, I. N. P.; NOBREGA, R. A. A.; ARAUJO, F. R. N. Modelagem de dados geográficos para otimização do estudo de um corredor ferroviário entre Paracatu-mg e Ipatinga-mg. In: XXVIII ANPET, 2014, Curitiba. Anais do XXVIII ANPET, 2014

SOUZA, I. N. P. Modelagem da relação da rede ferroviária de transportes e das mudanças de uso e cobertura do solo na divisa dos estados do Maranhão, Tocantins, Piauí e Bahia. 2017. 201 f. Dissertação (Mestrado). Universidade Federal de Minas Gerais, Instituto de Geociências. 2017.

SPELLERBERG, I.F. Ecological effects of roads and traffic: a literature review. Global Ecology and Biogeography, v.7, 1998; 333p.

THEOBALD, D. M. Estimating natural landscape changes from 1992 to 2030 in the conterminous US. Landscape Ecology, v. 25, p. 999-1011. 2010.

TROMBULAK, S. C.; FRISSELL, C. A. Review of Ecological Effects of Roads on Terrestrial and Aquatic Communities. Conservation Biology, [S.L], v. 14, n. 1, p. 18-30, fev. 2000.

VALEC. Ferrovias $\quad$ VALEC 2015.2 Disponível em: http://www.valec.gov.br/acoes_programas/Downloads/MapaFerroviasValec_15-06-2015. pdf.

VENCOVSKY, V. P. Sistema Ferroviário e o uso do território brasileiro: uma análise do movimento de produtos agrícolas. Dissertação de Mestrado, Instituto de Geociências da Universidade Estadual de Campinas. UNICAMP, V552s. 167p. Campinas, 2006.

VIEIRA, J. C., Desafios de Ferrovia da Integração Centro-Oeste no cerrado. Revista Brasileira de Desenvolvimento Regional, V.3, N.2, P.55-72. Blumenau. 2015. 